\title{
Factors influencing acceptability of voluntary HIV testing among pregnant women in Gamboma, Republic of Congo
}

\author{
Laure Stella Ghoma-Linguissi ${ }^{1}$, Dagene Fruinovy Ebourombi ${ }^{1}$, Anissa Sidibe ${ }^{1}$, Thomas Serge Kivouele ${ }^{1}$, \\ Jeannhey Christevy Vouvoungui ${ }^{1,3}$, Pierre Poulain ${ }^{1}$ and Francine Ntoumi ${ }^{1,2,3,4^{*}}$
}

\begin{abstract}
Background: This study was carried out to identify factors affecting the acceptability of voluntary HIV testing among pregnant women in a semi-rural city, Gamboma, Republic of Congo.

Methods: A cross-sectional study was conducted between January and September 2012. Pregnant women attending antenatal heath care at an integrated health center were enrolled after informed consent and followed through voluntary HIV testing.

Results: Among 136 participants, 98 women (72\%) accepted voluntary HIV testing after pre-test counseling. Women with basic education, those who cited blood transfusion as a mode of transmission and prevention of mother-to-child transmission (MTCT) were more likely to accept testing as well those informed about free HIV testing. Interestingly, pregnant women who had heard about HIV/AIDS from hospital setting were less likely to accept testing.
\end{abstract}

Conclusions: Our data indicate that increasing general education on HIV transmission/prevention modes is crucial for increasing acceptability of screening. Furthermore, HIV/AIDS knowledge disseminated to patients in hospital settings should be carefully monitored. Lastly, scaling-up MTCT services along with a better and larger community information, may address accessibility barriers observed in the present study.

Keywords: PMTCT, Women, HIV testing, Acceptability, Rural area, Republic of Congo

\section{Background}

Globally, 3.2 million children under 15 were living with HIV in 2013 [1] Over 700 children become newly infected with HIV each day [2]. The majority of children living with HIV were infected via mother-to-child transmission (MTCT), during pregnancy, labor, delivery or breastfeeding [3]. In comparison to other continents, Africa has the highest burden of the disease accounting for about $90 \%$ of pediatric HIV infections [4].

Prevention of mother-to-child transmission (PMTCT) of HIV remains a top priority in HIV/AIDS disease control efforts. Mother-to-child transmission has been

\footnotetext{
*Correspondence: fntoumi@fcrm-congo.com

1 Fondation Congolaise pour la Recherche Médicale, Cité OMS, villa D6,

Djoué, Brazzaville, Republic of Congo

Full list of author information is available at the end of the article
}

significantly reduced worldwide. In 2013, $16 \%$ of children born to women living with HIV became infected, compared to $26 \%$ in 2009 [1]. This decrease is particularly significant in high-income countries, where reduction of MTCT has been achieved through universal HIV screening of pregnant women and for those identified as HIV + through a three steps algorithm: (1) antiretroviral prophylaxis during pregnancy and labor, and antiretroviral ARV prophylaxis given to the infant in the first weeks of life; (2) obstetrical interventions including elective caesarean delivery (prior to onset of labor and membrane rupture); and (3) complete avoidance of breastfeeding [5-7]. Although complete avoidance of breastfeeding is an intervention of obvious utility, it may not be feasible in parts of the world where there is limited access to clean water and where there is no option than breastfeeding [8]. 
The World Health Organization (WHO) promotes a comprehensive approach to prevent MTCT based on four components [5, 9]. This approach includes (1) primary prevention of HIV among women at reproductive age; (2) preventing unintended pregnancies among women living with HIV; (3) preventing HIV transmission from a woman living with HIV to her infant through antiretroviral prophylaxis or treatment; and (4) providing appropriate treatment, care and support to mothers living with HIV and their children and families [10, 11].

The Republic of Congo (RoC) was one of the first countries in Africa to be affected by the HIV epidemic [12]. The HIV infection rate has declined among pregnant women in RoC from $3.4 \%$ in 2009 to $2.8 \%$ in 2012 as reported by the Congolese Ministry of Public Health. In comparison, HIV prevalence estimate was $3.2 \%$ in the adult population in 2011 [13]. Regarding MTCT, limited data are available. In 1989, Lallemant et al. showed that, in Brazzaville, infant mortality in children born to women living with HIV exceeded 260 per 1000, while it was only 44 per 1000 in children born to HIV-negative mothers [14]. In 1994, the same team also demonstrated that the MTCT rate was of $40.4 \%$ in Brazzaville [15]. These authors reported also an estimate MTCT rate of 25-40 \% in Pointe-Noire [16]. The high transmission of HIV from mother to child in RoC, led to the implementation of a MTCT prevention policy in 2001.

A first strategic plan (2003-2007) focused on several objectives: reduction of $20 \%$ of transmission rates; counseling and voluntary testing to all women during prenatal consultations; access to care and treatment, nutritional and psychological support for HIV positive mother and children [17]. The goal of the second strategic plan (2009-2013) in RoC aimed to improve the health of parents and their children by scaling up comprehensive PMTCT, paediatric HIV care and treatment, and support services. This resulted in major progresses with $18 \%$ of newborns born to HIV positive women testing HIV positive, 22 comprehensive PMTCT trainings and the acceptability rate of voluntary HIV testing of $79.4 \%$.

As the national HIV/AIDS program of RoC aims to move from prevention to elimination of MTCT, one of the key indicators is the increase of acceptability of HIV testing in pregnant women. The present study conducted in the semi-rural city of Gamboma where health services have established PMTCT program, is the first to investigate factors that may influence the acceptance of HIV screening during pregnancy.

\section{Methods}

\section{PMTCT program}

The PMTCT program is based on the national guidelines of RoC. The entry point for pregnant women is integrated health centers (Centre de Santé Intégré, CSI) and the reference hospital.

PTMCT starts with health education session including introduction to the voluntary counseling and all participating pregnant women are proposed to be tested for HIV. After this group counseling, the counselors pursue with individual counseling for those who consented to be tested for HIV on the same day. Women who needed more time to think about the implication of this test could be screened later at their convenience.

Pre- and post-counseling were conducted by a trained health officer who administered the questionnaire. HIV screening was performed by an experienced technician and results were available within $30 \mathrm{~min}$.

The investigator did not interfere with the normal procedure of the health facility, and was only present as an observer upon consent of study participant. The investigator was not present when the mid-wife provided the test result to the pregnant women. Pregnant women who were tested HIV positive, were referred to the local reference hospital where HIV health care including access to treatment and follow-up was provided.

\section{Study area and site}

The study was conducted in Gamboma, a semi-rural city located in the center of $\mathrm{RoC}$, in the department of Plateau, approximately $273 \mathrm{~km}$ from the capital city Brazzaville. It has an estimated population of forty three inhabitants with a reported HIV prevalence of $3.4 \%$ in women and $2.9 \%$ in men [18]. The study was carried out at the antenatal health care of the Gamboma I health facility. This center received the highest number of pregnant women for consultation and its medical staff had received formal training in PTMTC.

\section{Study design and population}

A cross-sectional study was conducted. The recruitment was done between January and September 2012. A member of the medical staff presented the study to all pregnant women attending the health facility. The inclusion criteria for the study was all pregnant women who had not been tested for HIV during their current pregnancy and who consented to the study through signed informed consent.

\section{HIV testing}

Following the national algorithm developed for the diagnosis of HIV in RoC, blood samples were tested using two rapid tests: Determine HIV $1 / 2$ test (Alere $\mathrm{GmbH}$, Koln, Germany) and ImmunoComb II HIV 1 \& 2 BiSpot (Orgenics, Yavne, Israel). In case of discordance between these two tests, the enzyme-linked immunosorbent assay (ELISA, Vironostika ${ }^{\circledR} \mathrm{HIV}-1$ Plus O Microelisa 
System, UK) was performed by the reference laboratory in $\mathrm{RoC}$ which is the Laboratoire National de Santé Publique at Brazzaville as previously described by Linguissi et al. [19]. In this study, no serological discordant case was reported.

\section{Data collection and quality control}

The following pieces of information were collected from the study participants using structured questionnaires: socio-demographic data (occupation, level of education, marital status), knowledge on HIV transmission, means of HIV prevention and acceptance of voluntary HIV screening. The study questionnaire was also translated and presented in two local languages (Lingala and Téké). Data coding and verification were performed by crosschecking the dataset at each step. The completeness and consistency of data was established by supervision of the principal investigator.

\section{Data processing}

A total of 136 pregnant women were recruited in the study. Data were entered using software Epilnfo (version 3.5.3; Centers for Disease Control and Prevention, Atlanta, USA).

\section{Data analysis}

Data were analyzed using SPSS software (version 16; IBM Corporation, New York, USA). Frequencies and proportions were used to describe the study population in relation to the relevant variables. Odds ratio, $95 \%$ confidence interval and $p$ value were computed to assess the presence and degree of association between acceptance of HIV testing and knowledge on HIV and MTCT. Logistic regression was the only statistic method used to compute that parameters. All statistical tests were significant when $p$ value $<0.05$.

\section{Ethical statement}

The study was approved by the Institutional Ethics Committee for Scientific Research and Health (CERSSA) (approval reference 00000067/DGRST/CERSSA) on the 30 March 2012. Permission to conduct the study was also obtained from the primary coordinator of the health worker in charge of the health facility. Women were informed about the nature of the study before enrolling in the study. If needed, discussions were translated in a local language (Lingala and Téké) by the investigators. The informed written consent of each woman was individually obtained and interviews were conducted in a place where the informant felt secure. The confidentiality of the discussion and of collected data was ensured. The interview was stopped at the convenience of the informant.

\section{Results}

Socio-demographic characteristics of the pregnant women Table 1 shows socio-demographic characteristics of the 136 pregnant women enrolled in the study. The mean age was $25.5 \pm 7.6$ years within an interval ranging from 14 to 45 years. Approximately, $83 \%$ of the women had a basic education level comprising of primary $(34 \%)$ and middle school (49\%). With regards to professional occupation, $39 \%$ were farmer, $31 \%$ housewives, $15 \%$ saleswomen in markets and $13 \%$ students. We also found that $63 \%$ of the pregnant women were unmarried, $35 \%$ were married or living as husband and wife, and $3 \%$ were divorced or separated or widows.

The influence of socio-demographic variables on the acceptance to voluntary HIV testing was assessed. No significant effect was observed between the age of pregnant women, professional occupation, marital situation and acceptance of HIV testing. However, pregnant women with primary and middle school education were four and five times more likely to accept HIV testing than women having no education.

\section{Knowledge of prevention and transmission modes of HIV/ AIDS}

From the 136 pregnant women recruited in this study, 98 (72\%) women accepted to be screened for HIV. Ninetythree percent of the women had heard about HIV/AIDS (Table 2). Pregnant women had heard of the disease mainly from parents/friends (73\%), within hospital settings or health facility (60\%) and in religious or school settings (32\%). Traditional media such as newspapers, books, radio and TV were less cited ( $26 \%$ for radio and $\mathrm{TV}$ and $2 \%$ for newspapers and books).

With regards to the modes of HIV transmission, unprotected sexual intercourse was cited among $82 \%$ of the women, followed by contaminated objects $(70 \%)$ and MTCT (57\%). Blood transfusion was cited last with $23 \%$.

The most cited prevention modes of contamination were condoms use (71\%), avoid cutting objects (56\%), fidelity between partners (46\%) and PMTCT (43\%). Abstinence was at the bottom of the list (12\%).

Women who have been informed of HIV at the hospital or health facility were three times less likely to accept HIV testing. Among the modes of HIV transmission, pregnant women informed about the risk to get HIV through blood transfusion were four times more likely to accept HIV testing. Pregnant women who cited the PMTCT program among one of prevention modes of HIV transmission were two times more likely to accept HIV testing.

As shown in Table 2, pregnant women who knew HIV testing was free of charge represented $66 \%$ of all participants and were seven times more likely to accept HIV 
Table 1 Influence of socio-demographic characteristics on acceptability of HIV testing in pregnant women, Gamboma, Republic of Congo

\begin{tabular}{|c|c|c|c|c|}
\hline & $\begin{array}{l}\text { Number of individual } \\
N(\%)\end{array}$ & $\begin{array}{l}\text { Accept to do HIV test } \\
N(\%)\end{array}$ & Odds ratio $(95 \% \mathrm{Cl})$ & $P$ value \\
\hline \multicolumn{5}{|l|}{ Age (years) } \\
\hline $14-24$ & $67(49)$ & $47(70)$ & Reference & \\
\hline $25-35$ & $53(39)$ & $41(77)$ & $0.94(0.45-1.94)$ & 0.860 \\
\hline$\geq 35$ & $16(12)$ & $10(63)$ & $0.56(0.18-1.69)$ & 0.553 \\
\hline \multicolumn{5}{|l|}{ Education level } \\
\hline No education & $16(12)$ & $10(63)$ & Reference & \\
\hline Primary school & $47(34)$ & $37(79)$ & $4.05(1.13-14.43)$ & $0.031^{*}$ \\
\hline Middle school & $67(49)$ & $48(72)$ & $5.01(1.46-17.33)$ & $0.010^{*}$ \\
\hline High school & $5(4)$ & $2(40)$ & $4.50(0.54-37.38)$ & 0.164 \\
\hline University & $1(1)$ & $1(100)$ & - & \\
\hline \multicolumn{5}{|l|}{ Professional occupation } \\
\hline Farmer & $53(39)$ & $37(70)$ & Reference & \\
\hline Student & $18(13)$ & $13(72)$ & $1.76(0.59-5.24)$ & 0.310 \\
\hline Housewife & $42(31)$ & $33(79)$ & $2.24(0.97-5.18)$ & 0.059 \\
\hline Saleswoman & $20(15)$ & $12(60)$ & $1.37(0.48-5.17)$ & 0.551 \\
\hline Others & $3(2)$ & $3(100)$ & $2.24(0.19-26.22)$ & 0.521 \\
\hline \multicolumn{5}{|l|}{ Marital status } \\
\hline Unmarried & $85(62)$ & $64(75)$ & Reference & \\
\hline Married or cohabiting & $47(35)$ & $31(66)$ & $1.30(0.63-2.69)$ & 0.551 \\
\hline Divorced or separated or widows & $4(3)$ & $1(75)$ & $0.27(0.03-2.70)$ & 0.521 \\
\hline
\end{tabular}

Table 2 Influence of knowledge of HIV/AIDS transmission/prevention modes on acceptability of HIV testing in pregnant women, Gamboma, Republic of Congo

\begin{tabular}{|c|c|c|c|c|}
\hline & $\begin{array}{l}\text { Number of individuals } \\
\mathrm{N}(\%)\end{array}$ & $\begin{array}{l}\text { Accept to do HIV test } \\
\mathrm{N}(\%)\end{array}$ & Odds ratio (95 \% Cl) & $P$ value \\
\hline Heard of HIV/AIDS & $127(93)$ & $91(72)$ & $0.63(0.12-3.34)$ & 0.590 \\
\hline \multicolumn{5}{|l|}{ Where did you hear about HIV/AIDS? } \\
\hline Media (radio, TV) & $35(26)$ & $28(80)$ & $1.77(0.70-4.49)$ & 0.228 \\
\hline News paper, books & $3(2)$ & $2(67)$ & $0.77(0.07-8.95)$ & 0.847 \\
\hline Religion/school & $43(32)$ & $34(79)$ & $1.71(0.73-4.03)$ & 0.218 \\
\hline Parents/friends & $96(71)$ & $70(73)$ & $1.15(0.51-2.60)$ & 0.730 \\
\hline Hospital & $68(50)$ & $41(60)$ & $0.29(0.13-0.66)$ & $0.003^{*}$ \\
\hline \multicolumn{5}{|l|}{ Mode of HIV/AIDS transmission } \\
\hline Unprotected sexual intercourse & $111(82)$ & $83(75)$ & $1.95(0.77-4.91)$ & 0.155 \\
\hline Contaminated objects & $95(70)$ & $73(75)$ & $2.14(0.97-3.41)$ & 0.060 \\
\hline Blood transfusion & $31(23)$ & $28(90)$ & $4.45(1.26-15.73)$ & $0.021^{*}$ \\
\hline MTCT & $77(57)$ & $58(75)$ & $1.44(0.67-3.07)$ & 0.346 \\
\hline \multicolumn{5}{|l|}{ Prevention of HIV/AIDS } \\
\hline РMTCT & $58(43)$ & $47(81)$ & $2.37(1.05-5.36)$ & $0.038^{*}$ \\
\hline Condom & $96(71)$ & $72(75)$ & $1.59(0.70-3.59)$ & 0.267 \\
\hline Fidelity & $63(46)$ & $50(79)$ & $1.98(0.90-4.33)$ & 0.087 \\
\hline Abstinence & $16(12)$ & $13(81)$ & $1.92(0.51-7.27)$ & 0.335 \\
\hline Avoid cutting objects & $76(56)$ & $59(78)$ & $2.06(0.94-4.51)$ & 0.070 \\
\hline Knowledge of free HIV testing & $90(66)$ & $77(86)$ & $6.99(3.02-16.19)$ & $P<0.001^{*}$ \\
\hline Knowledge of the existence of a HIV testing center & $70(51)$ & $58(83)$ & $3.06(1.37-6.79)$ & $0.006^{*}$ \\
\hline
\end{tabular}

* statistically different 
testing. With regards to the existence of a health care center, $51 \%$ knew its existence. These women were three times more likely to accept HIV testing.

\section{Discussion}

The present study is the first to report the acceptability of voluntary HIV testing among pregnant women in a rural city, Gamboma, in RoC. We found that $72 \%$ of pregnant women accepted HIV testing. This observation is comparable to what is observed in other subSaharan African countries [20]. Albeit encouraging, a higher acceptance of HIV testing among pregnant women is crucial if one wants to eliminate new HIV infections among infants.

Given that we observed an HIV prevalence of $11 \%$ among pregnant women in Gamboma, this means that among the 38 women who refused HIV screening, four women might have been HIV infected and missed for PMTCT interventions. It is plausible that women who refused HIV testing refused it because they knew or believed they had behavioral risks and therefore might be infected. Hence the proportion of missed opportunities for PMTCT could be higher than what has been calculated on the basis of $11 \%$ HIV prevalence in Gamboma. To further increase the coverage of voluntary HIV testing, the opt-out approach for HIV-testing at antenatal care services may be considered as several African countries already adopted it [20].

The socio-demographic characteristic of the pregnant women recruited in the study is reminiscent to that observed in similar studies conducted in rural African settings [21-23], characterized by a low level of education and farming as the primary occupation. Approximately $2 / 3$ of the pregnant women in our cohort were unmarried but no association was found between marital status and the acceptability of HIV testing, even though previous studies including one conducted in $\mathrm{RoC}$ [24] and in South Africa [25] reported an association between HIV incidence and marital status.

Pregnant women who attended primary or middle school accepted HIV test up to five times more than women with no education. The group of "high school or university" was too small to allow any interpretation regarding the influence of education level on the acceptance of HIV test. However, education plays a key role in the understanding of HIV counseling and has been found to be associated with Voluntary Counseling and Test (VCT) acceptance [26-29].

In the present work, our findings showed that $93 \%$ of pregnant women knew that HIV/AIDS was a transmissible disease. We noticed that women were less informed about PMTCT then unprotected sexual transmission suggesting that specific effort should be done by the national HIV control program towards women, for example through community based approaches [30,31].

The most interesting finding was the association observed between the source of HIV/AIDS information and the acceptability to HIV testing. Pregnant women who had heard of the disease in hospital and health facilities were three times less likely to accept HIV testing. One explanation could be a relative fear regarding hospitalization or a psychological disturbance related to admission in a health facility. Also the way counseling is performed could be another explanation. Issues surrounding counseling are known to represent a major challenge in HIV test acceptance [32,33]. In the case of PMTCT, the quality of pre-counselling is a key factor influencing the acceptance of HIV testing among pregnant women [34, 35].

It is important to highlight the fact that this study has been conducted in rural health facilities, therefore the findings may not be generalized to urban facilities. There are significant differences in the socio-demographic structure of populations that live in urban versus rural areas, with urban population being more educated and economically advantaged compared to rural population $[36,37]$.

To reduce MTCT, mechanisms to increase participation in HIV testing among pregnant women are essential. Firstly, it is important to raise awareness about the good efficiency of PMTCT. Secondly, it would be desirable to involve men or partners to participate in prenatal visits in order to limit the fear of rejection or discrimination.

One limitation of this study was that interviews were conducted by the same midwives who performed voluntary counseling and test (VCT). This may have influenced results, and precluded analysis of whether characteristics of the pre-test counselling received affected acceptance rates. Another limitation is the small sample size of the cohort albeit the enrollment period ran nine months. Notwithstanding these limitations, we believe that our study has very important findings for strengthening PMTCT implementation in Gamboma and in the country.

The current HIV/AIDS campaign momentum in the RoC should be strengthened. More media or radio talks should be aired to educate families and community members on HIV/AIDS issues. The community action to reduce stigma around HIV/AIDS should be encouraged. The pregnant women's partner involvement in the process of HIV counseling and testing is essential if pregnant women are expected to fully participate and benefit from PMTCT programs. 


\section{Conclusion}

This first study conducted among pregnant women in a semi-rural area of the Republic of Congo showed that level of education and general knowledge of HIV transmission/prevention are barriers to the acceptability of voluntary HIV testing. There is a need to scaling up mass information targeting this specific population for ensuring that newborns will be protected from the infection.

\section{Authors' contributions}

AS was involved in the study design, data analysis and manuscript writing, DFE participated in data collection and analysis; TSK was involved in study design and data analysis; JCV was in charge of data analysis and LSGL was involved in data analysis and manuscript writing, FN was responsible of overall study. All authors participated in the critical revision of the manuscript. All authors read and approved the final manuscript.

\section{Author details \\ ${ }^{1}$ Fondation Congolaise pour la Recherche Médicale, Cité OMS, villa D6, Djoué, Brazzaville, Republic of Congo. ${ }^{2}$ Faculty of Health Sciences, Marien Ngouabi University, Brazzaville, Republic of Congo. ${ }^{3}$ Faculty of Sciences and Tech- niques, Marien Ngouabi University, Brazzaville, Republic of Congo. ${ }^{4}$ Institute for Tropical Medicine, University of Tübingen, Tübingen, Germany.}

\section{Acknowledgements}

We would like to thank the pregnant women who participated in this study and the medical staff of the community health center and base hospital of Gamboma for their advice and support in this study. LSGL, JCV, KT, DE were supported by CANTAM Network training grants. This work was supported by CANTAM (Central Africa Network on Tuberculosis, HIV/AIDs and Malaria), a network of excellence funded by European and Developing Countries Clinical Trials Partnership (EDCTP).

\section{Competing interests}

The authors declare that they have no competing interests.

Received: 24 May 2015 Accepted: 29 October 2015

Published online: 06 November 2015

\section{References}

1. UNAIDS. Report on the Global AIDS epidemic;2013.

2. UNAIDS. Children and pregnant women living with HIV. The GAP report; 2014.

3. UNAIDS. Beginning of the end of the AIDS epidemic. The Gap Global report; 2014.

4. Bernays S, Jarrett P, Kranzer K, Ferrand RA. Children growing up with HIV infection: the responsibility of success. Lancet. 2014;383:1355-7.

5. Anoje C, Aiyenigba B, Suzuki C, Badru T, Akpoigbe K, Odo M, Odafe S, Adedokun O, Torpey K, Chabikuli ON. Reducing mother-to-child transmission of HIV: findings from an early infant diagnosis program in southsouth region of Nigeria. BMC Public Health. 2012;12:184.

6. Johri M, Ako-Arrey D. The cost-effectiveness of preventing mother-tochild transmission of HIV in low- and middle-income countries: systematic review. Cost Eff Resour Alloc. 2011;9:3.

7. Horvath T, Madi BC, luppa IM, Kennedy GE, Rutherford G, Read JS. Interventions for preventing late postnatal mother-to-child transmission of HIV. Cochrane Database Syst Rev. 2009;CD006734.

8. Read JS, Newell MK. Efficacy and safety of cesarean delivery for prevention of mother-to-child transmission of HIV-1. Cochrane Database Syst Rev. 2005;CD005479.

9. Doherty T, Chopra M, Nkonki L, Jackson D, Greiner T. Effect of the HIV epidemic on infant feeding in South Africa: "when they see me coming with the tins they laugh at me". Bull World Health Organ. 2006:84:90-6.
10. WHO. PMTCT Strategic Vision 2010-2015: preventing mother-to-child transmission of HIV to reach the UNGASS and millennium development goals. Geneva. WHO;2013.

11. WHO. Guidelines on HIV and infant feeding 2010. Principles and recommendations for infant feeding in the context of HIV and a summary of evidence. Geneva. WHO;2010.

12. WHO. Antiretroviral drugs for treating pregnant women and preventing HIV infection in infants: recommendations for a public health approach. Geneva.: WHO; 2010.

13. Faria NR, Rambaut A, Suchard MA, Baele G, Bedford T, Ward MJ, Tatem AJ, Sousa JD, Arinaminpathy N, Pepin J, Posada D, Peeters M, Pybus OG, Lemey P. The early spread and epidemic ignition of HIV-1 in human populations. Science. 2014;346:56-61.

14. CNLS. Enquete de Seroprevalence et Sur Les Indicateurs Du Sida Du Congo ESISC-I. UNICEF/UNFPA; 2009 [Ed L. CNSE, ICF, Macro].

15. Lallemant M, Lallemant-Le-Coeur S, Cheynier D, Nzingoula S, Jourdain G, Sinet M, Dazza MC, Blanche S, Griscelli C, Larouzé B. Mother-child transmission of HIV-1 and infant survival in Brazzaville. Congo. AIDS Lond Engl. 1989;3:643-6.

16. Lallemant $M$, Le Coeur S, Samba L, Cheynier D, M'Pelé P, Nzingoula S, Essex M. Mother-to-child transmission of HIV-1 in Congo Central Africa. Aids. 1994:8(10):1451-6.

17. Bisio F, Masini G, Blasi Vacca E, Calzi A, Cardinale F, Bruzzone B, Bruzzi P, Viscoli C, Kento-Mwana group, Nkouendolo JP, Moutou J, Banguissa H, Nicolini L, Schenone E, Repetto E, Montaldo C, Ferrando S, Righi E, Dentone C, Farinella ST, Vitale F, Izzo M, Mularoni A, Mikulska M, Di Stefano L, Malfatto E, Bernardini C, Ginocchio F, Secondo G, Delfino E, et al. Effectiveness of a project to prevent HIV vertical transmission in the Republic of Congo. J Antimicrob Chemother. 2013;68:1862-71.

18. CREDES. Rapport Stratégie National de Communication En Matière de Lutte Contre Le VIH/SIDA 2003-2007. RAPPORT FINAL_Projet de Lutte Contre Le VIH/SIDA et de Santé. Brazzaville, Congo: Banque Mondiale.

19. Linguissi LS, Mayengue P, Sidibé A, Vouvoungui JC, Missontsa M, MadzouLaboum I, Essassa G, Oyakhirome S, Frank M, Penlap V, Ntoumi F. Prevalence of national treatment algorithm defined smear positive pulmonary tuberculosis in HIV positive patients in Brazzaville, Republic of Congo. BMC Res Notes. 2014;7:578.

20. Wettstein C, Mugglin C, Egger M, Blaser N, Vizcaya LS, Estill J, Bender N, Davies M-A, Wandeler G, Keiser O. Missed opportunities to prevent mother-to-child-transmission: systematic review and meta-analysis. AIDS. 2012;26:2361-73.

21. Conrad P, De Allegri M, Moses A, Larsson EC, Neuhann F, Muller O, Sarker M. Antenatal care services in rural Uganda: missed opportunities for good-quality care. Qual Health Res. 2012;22:619-29.

22. Larsson EC, Thorson A, Pariyo G, Conrad P, Arinaitwe M, Kemigisa M, Eriksen J, Tomson G, Ekstrom AM. Opt-out HIV testing during antenatal care: experiences of pregnant women in rural Uganda. Health Policy Plan. 2012;27:69-75.

23. Larsson EC, Thorson AE, Pariyo G, Waiswa P, Kadobera D, Marrone G, Ekström AM. Missed opportunities: barriers to HIV testing during pregnancy from a population based cohort study in rural Uganda. PLoS One. 2012;7:e37590.

24. Lallemant M. Lallemant-Le Coeur S, Cheynier D, Nzingoula S, Jourdain G, Sinet M, Dazza MC, Larouzé B. Characteristics associated with HIV-1 infection in pregnant women in Brazzaville, Congo. J Acquir Immune Defic Syndr. 1992;5:279-85.

25. Shisana O, Zungu-Dirwayi N, Toefy Y, Simbayi LC, Malik S, Zuma K. Marital status and risk of HIV infection in South Africa. South Afr Med J Suid-Afr Tydskr Vir Geneeskd. 2004;94:537-43.

26. Arulogun OS, Adewole IF, Olayinka-Alli L, Adesina AO. Community gate keepers' awareness and perception of prevention of mother-to-child transmission of HIV services in Ibadan. Nigeria. Afr J Reprod Health. 2007;11:67-75.

27. Orne-Gliemann J, Mukotekwa T, Miller A, Perez F, Glenshaw M, Nesara P, Dabis F. Community-based assessment of infant feeding practices within a programme for prevention of mother-to-child HIV transmission in rural Zimbabwe. Public Health Nutr. 2006;9:563-9.

28. Coovadia HM. Access to voluntary counseling and testing for HIV in developing countries. Ann NY Acad Sci. 2000;918:57-63. 
29. Koo DJ, Begier EM, Henn MH, Sepkowitz KA, Kellerman SE. HIV counseling and testing: less targeting, more testing. Am J Public Health. 2006;96:962-4.

30. Hardon A, Vernooij E, Bongololo-Mbera G, Cherutich P, Desclaux A, Kyaddondo D, Ky-Zerbo O, Neuman M, Wanyenze R, Obermeyer C. Women's views on consent, counseling and confidentiality in PMTCT: a mixedmethods study in four African countries. BMC Public Health. 2012;12:26.

31. Chopra M, Doherty T, Jackson D, Ashworth A. Preventing HIV transmission to children: quality of counselling of mothers in South Africa. Acta Paediatr Oslo Nor. 1992;2005(94):357-63.

32. Peltzer K, Jones D, Weiss SM, Shikwane E. Promoting male involvement to improve PMTCT uptake and reduce antenatal HIV infection: a cluster randomized controlled trial protocol. BMC Public Health. 2011;11:778.

33. Becker S, Mlay R, Schwandt HM, Lyamuya E. Comparing couples' and individual voluntary counseling and testing for HIV at antenatal clinics in Tanzania: a randomized trial. AIDS Behav. 2010;14:558-66.
34. Bajunirwe F, Muzoora M. Barriers to the implementation of programs for the prevention of mother-to-child transmission of HIV: a cross-sectional survey in rural and urban Uganda. AIDS Res Ther. 2005;2:10.

35. Painter TM, Diaby KL, Matia DM, Lin LS, Sibailly TS, Kouassims MK, Ekpini ER, Roels TH, Wiktor SZ. Sociodemographic factors associated with participation by HIV-1-positive pregnant women in an intervention to prevent mother-to-child transmission of HIV in Cote d'Ivoire. Int J STD AIDS. 2005; 16:237-42

36. Gourlay A, Wringe A, Todd J, Cawley C, Michael D, Machemba R, Reniers G, Urassa M, Zaba B. Factors associated with uptake of services to prevent mother-to-child transmission of HIV in a community cohort in rural Tanzania. Sex Transm Infect. 2015;91(7):520-7.

37. Manyahi J, Jullu BS, Abuya MI, Juma J, Ndayongeje J, Kilama B, Sambu V, Nondi J, Rabiel B, Somi G, Matee MI. Prevalence of HIV and syphilis infections among pregnant women attending antenatal clinics in Tanzania, 2011. BMC Public Health. 2015;15:501.

\section{Submit your next manuscript to BioMed Central and take full advantage of:}

- Convenient online submission

- Thorough peer review

- No space constraints or color figure charges

- Immediate publication on acceptance

- Inclusion in PubMed, CAS, Scopus and Google Scholar

- Research which is freely available for redistribution

Submit your manuscript at www.biomedcentral.com/submit
C Biomed Central 